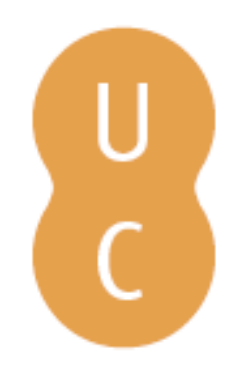

\title{
pompalina
}

\section{Roma nas Vidas Paralelas de Plutarco}

Autor(es): Pinheiro, Joaquim

Publicado por: Associação Portuguesa de Estudos Clássicos; Imprensa da

Universidade de Coimbra

URL

persistente: URI:http://hdl.handle.net/10316.2/31791

DOI: $\quad$ DOI:http://dx.doi.org/10.14195/978-989-721-069-3_29

Accessed : $\quad$ 26-Apr-2023 12:27:27

A navegação consulta e descarregamento dos títulos inseridos nas Bibliotecas Digitais UC Digitalis, UC Pombalina e UC Impactum, pressupõem a aceitação plena e sem reservas dos Termos e Condições de Uso destas Bibliotecas Digitais, disponíveis em https://digitalis.uc.pt/pt-pt/termos.

Conforme exposto nos referidos Termos e Condições de Uso, o descarregamento de títulos de acesso restrito requer uma licença válida de autorização devendo o utilizador aceder ao(s) documento(s) a partir de um endereço de IP da instituição detentora da supramencionada licença.

Ao utilizador é apenas permitido o descarregamento para uso pessoal, pelo que o emprego do(s) título(s) descarregado(s) para outro fim, designadamente comercial, carece de autorização do respetivo autor ou editor da obra.

Na medida em que todas as obras da UC Digitalis se encontram protegidas pelo Código do Direito de Autor e Direitos Conexos e demais legislação aplicável, toda a cópia, parcial ou total, deste documento, nos casos em que é legalmente admitida, deverá conter ou fazer-se acompanhar por este aviso.

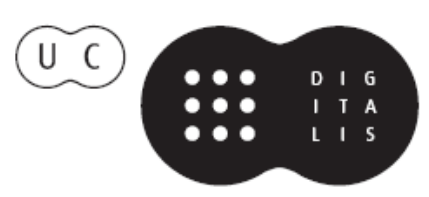




\section{Espaços e Paisagens}

\section{Antiguidade Clássica e Heranças Contemporâneas}

Vol. I Línguas e Literaturas. Grécia e Roma

Francisco de Oliveira, Cláudia Teixeira, Paula Barata Dias (coords.)

IMPRENSA DA UNIVERSIDADE DE COIMBRA 


\title{
ROMA NAS VIDAS PARALELAS DE PLUTARCO
}

\author{
Joaquim Pinheiro \\ Universidade da Madeira
}

\begin{abstract}
Plutarch's biographic techne promotes a cultural krasis, without annihilating the specificities of both Greek and Roman cultures which are the pivotal axis of the parallel structure of the Lives. With this context in mind, it is our goal to identify the primordial elements in the description of Rome, a space which assumes a different meaning than those of Athens or Delphi in the work of the author from Queronea.
\end{abstract}

Keywords: Parallel Lifes, Plutarch, Rome.

Palavras-chave: Plutarco, Roma, Vidas Paralelas.

A descrição que Plutarco faz de Roma tem subjacente um tema que nem sempre é consensual entre os estudiosos das Vidas Paralelas e mesmo dos Tratados Morais: a definição da relação do autor com a Vrbs. Plutarco, um aristocrata que se considera digno de assumir responsabilidades públicas ${ }^{1}$, estabelece um equilíbrio entre o poderio romano e a débil situação helénica, defendendo que a manutenção da harmonia deve ser o principal objectivo do político grego ${ }^{2}$. Antes de Plutarco, já Políbio e Dionísio de Halicarnasso tinham tratado da história romana, no entanto, o que distingue verdadeiramente as Vidas Paralelas é o facto de nelas se colocar em paralelo, de forma sistemática e metodológica, a história grega e a história romana, sugerindo-se que a história política e militar dos Gregos pode ser comparada ao imperium ${ }^{3}$.

A Vrbs, como Plutarco afirma na biografia de Rómulo (8.9), foi fundada por

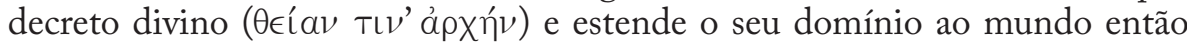
conhecido por causa da arete dos seus heróis e da vontade divina, conexão que o autor também estabelece no tratado De fortuna romanorum 320A ${ }^{4}$ : Quem

${ }^{1}$ Em Cim. 1.1 e De sera num. uind. 558A, Plutarco revela pertencer à aristocracia, até porque tem ascendência real.

${ }^{2}$ Cf. 824B-E; M. Lopez Salvà (1990-1: 25-36) mostra como Plutarco e Díon de Prusa, com realismo, aconselham as populações a ter uma atitude cooperante com Roma, sem renunciar à legítima aspiração pela autonomia.

${ }^{3}$ Em Cic. 41.1, Plutarco refere que Cícero projectava escrever uma história nacional com vários elementos da história grega, ou seja, uma obra com uma ideologia semelhante ao paralelismo plutarquiano, embora com uma perspectiva mais romana.

${ }^{4}$ No mesmo tratado, Plutarco refere que a tyche e o daimon conduziram os Romanos aos feitos mais célebres e à sua grandeza, mas também se deve imputar à tyche a origem dos maiores desastres: os Celtas acamparem no Capitólio e sitiarem a Acrópole ou o assalto nocturno dos 
não diria sobre o nascimento, a salvação, a criação e o crescimento de Rómulo que a Fortuna colocou os fundamentos e a Virtude acabou a construção? Tendo este pensamento sempre presente, Plutarco dirige aos Romanos e aos Gregos, estes ainda receosos com a realidade do Império, uma mensagem que oscila entre o louvor da antiga Grécia e o reconhecimento do destino imperial de Roma. Sabendo-se que a literatura da Época Imperial e, em especial, da Segunda Sofística está marcada pelo compromisso entre a cultura grega e o império romano $^{5}$, as Vidas Paralelas denotam o encontro entre cultura e poder, ainda que os heróis romanos não se distingam apenas pelas suas conquistas, mas também pelo seu helenismo, como é o caso de Marcelo, Emílio Paulo ou Luculo.

Vejamos, em particular, o par biográfico Teseu-Rómulo, pelo facto de ambos serem heróis fundacionais. Com menos pormenor do que Dionísio de Halicarnasso (e.g., Ant. Rom. I.19.2, 17-21, 72-73), Plutarco indica várias teorias sobre a origem de Roma e do seu nome, ao aludir à origem etimológica de Roma, que derivaria de Rome ("valentia", "coragem"), denominação dada pelos Pelasgos, querendo com isso provar a origem helénica da Vrbs. Para reforçar esta afirmação, Plutarco lembra o facto de Evandro ter chegado à cidade antes de Eneias (Cf. Rom. 15.4; Marc. 8.7; Num. 7.10). Embora aponte estas raízes helénicas de roma, não atribui especial significado à influência da língua grega na língua latina, como é manifesto nas biografias de Marcelo (22.7) e Numa (7.10-11 e 13.9-10)

$\mathrm{Na}$ biografia de Camilo (22.3), refere-se a Roma como cidade grega

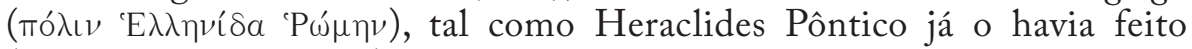
(cf. FGrHist 840 F 23). Note-se que também Dionísio de Halicarnasso (Ant. Rom. 1.89.1; cf. 1.5.1), dentro da sua abordagem profundamente helenocêntrica ${ }^{7} \mathrm{da}$ história romana, apresenta Roma como uma polis grega, fundada por Gregos, com uma língua que não passava de um dialecto do Grego e cujo sucesso se justifica pela adesão dos Romanos à arete helénica, ideia que Plutarco, em parte, corrobora na biografia de Catão Censor ${ }^{8}$. Apesar disso, o historiador e retor de Halicarnasso, que viveu vários anos em Roma após 30 a. C., salienta que, embora tenham acolhido vários povos

Gauleses (cf. ibid. 324D ss.); sobre a natureza dupla do sucesso romano, vide De glor. Athen. 345E, 348E, Flam. 11.5 e Comp. Arist.-Cat. Ma. 1.3; registem-se, a propósito desta matéria, as palavras de S. Swain (1989a: 508): "The idea that arete needs the additional factors tyche and $d y$ namis telesiourgos (Sol.-Publ. synk. 3.5, Dion 1.3) is fundamental to Plutarch's thought elsewhere and to his conception here of Rome's rise to greatness"; o mesmo estudioso, num outro artigo (1989b: 272-302), defende que Plutarco acreditava num passado pré-determinado e que o sucesso de Roma se devia à providência divina.

${ }^{5}$ Cf. S. Said et al. (2004: 453).

${ }^{6}$ Ver, ainda, Marcelo 5.5 e Quaest. conu. 274C. Segundo C. Ando (1999: 7), "It is easy enough to suggest that Greeks of the second century B.C. viewed Rome and her empire as two distinct entities, a polis that conquered many territories and an empire that possessed no more affective cohesion than a Hellenistic kingdom"

7 Por causa dessa perspectiva de Dionísio de Halicarnasso, R. Preston (2001: 100) afirma que "for Dionysius, there is no Roman culture".

${ }^{8}$ Cf. F. Hartog 1991 e E. Gabba 1991: 109-110. 
bárbaros, os Romanos não se deixaram, como outros, barbarizar: ${ }^{9}$

"Enquanto outros, ao habitarem entre Bárbaros, esqueceram, em pouco tempo, tudo o que era próprio dos Gregos, de modo que não falam a lingua grega, nem conservam os costumes dos Gregos, nem reconhecem os mesmos deuses, nem têm leis adequadas."

Também Plutarco, sem enfatizar a ideia da inferioridade romana ${ }^{10}$, distingue os Romanos dos Bárbaros. Na parte inicial da biografia de Marcelo, quando descreve os momentos que se seguiram ao final da Primeira Guerra Púnica (263-241 a. C.) e o receio dos Romanos devido à proximidade dos Gauleses, Plutarco, recusando classificar os Romanos como um povo bárbaro, alude à influência helénica nos sacrifícios realizados pelos Romanos: ${ }^{11}$

"De facto, os Romanos não praticavam nenhum rito bárbaro nem estrangeiro, mas seguiam o mais possivel as crenças dos Gregos e eram brandos em relação às coisas divinas. Como bárbaros são, no entanto, classificados os Gauleses. "12

Retomando o par fundacional, refira-se que, segundo Plutarco, Rómulo para consolidar a união entre Romanos e Sabinos aceitou partilhar o poder com Tácio e promoveu a organização militar e administrativa do seu povo, dando forma aos principais órgãos políticos que continuariam a funcionar na República. Foi também o responsável pela vocação militar do povo Romano, o que foi decisivo para a grandeza futura da $V r b s$.

Ao juntar Teseu e Rómulo num par biográfico, Plutarco realçará os vários aspectos em comum destas duas personagens (Thes. 2): são filhos ilegítimos, mas gozaram da fama de descenderem de deuses; associaram nas suas acções a inteligência à força; raptaram mulheres; sofreram infortúnios e vinganças; e, no final das suas vidas, viveram momentos de conflito com os seus concidadãos. $\mathrm{O}$ biógrafo esforça-se, assim, por dar uma dimensão histórica às suas personagens, numa tentativa de racionalização mitológica, sem ignorar os valores éticos dos seus heróis, e aproximando, dessa forma, as duas culturas. No entanto, à cidade de Atenas faltou, como a synkrisis do par evidenciará, a valorização do

\footnotetext{
9 Ant. Rom. 1.89.4. À semelhança de Heródoto, Dionísio de Halicarnasso refere a língua grega, os costumes e a religião, mas, em contrapartida, junta a estes elementos as leis (nomoi) e, acima de tudo, não alude à questão do Omaimon, para definir a grecidade. Logo, o segundo texto, revelador da evolução do sentido de to hellenikon, está mais próximo daquilo que Plutarco pensa sobre a possibilidade de partilhar uma cultura e adequa-se melhor à nova estrutura social que preconiza.

${ }^{10}$ Cf. A. Nikolaidis 1986: 229-244; para Díon de Prusa, ao contrário de Plutarco, os Romanos são bárbaros cf. Or. 32.40, 45.1, sendo a cultura grega superior; vide E. Bowie 1991: 194-201.

${ }^{11}$ Marc. 3.6; em Pel. 21.6, expressa com maior clareza o que pensa sobre os sacrifícios; sobre a influência helénica na religiosidade romana vide Num. 1.

${ }^{12}$ Cf. Marc. 8.1: o escudo de um bárbaro que Marcelo oferece ao deus; a propósito deste episódio, vide Val. Max. 3.2.5, Flor. 1.20.5 e Eutr. 3.6.
} 
vínculo conjugal que lhe permitiria criar uma estrutura social mais sólida, algo que Rómulo não neglicenciou na construção de Roma e que viria a ser um dos pilares do sucesso da Vrbs. Além disso, em Atenas, a ausência de um líder, uma vez que as aventuras de Teseu o ocupam mais do que o governo da cidade, mais não trouxe do que a confusão social (cf. Thes.32.1).

Assim, além da ajuda divina, a outra razão que, para Plutarco, mais contribuiu para a grandeza de Roma foi a política de assimilação dos povos vencidos, pacificando-os e fazendo-os participar dos direitos de cidadania. Em relação ao episódio do rapto das Sabinas, Dionísio de Halicarnasso (Ant. Rom. 2.34.1), numa perspectiva menos filo-romana, tem uma interpretação diferente, critica Rómulo por ter transformado os homens e os seus filhos em escravos, versão que, obviamente, não serve a idealização plutarquiana da imagem de Rómulo ${ }^{13}$.

Na biografia de Marcelo, por sua vez,Plutarco estrutura a narrativa biográfica em função da ligação do Romano à cultura helénica. Isso transparece, por exemplo, quando omite os crimes cometidos pelos Romanos na Sicília, por preferir realçar o comportamento justo de Marcelo, capaz de se equiparar aos valores helénicos, fazendo dele o primeiro Romano a mostrar aos Gregos que os Romanos também podiam ser justos. Talvez por querer provar que estes não eram um povo exclusivamente vocacionado para a realização de feitos guerreiros, Plutarco idealiza, com algum exagero, a figura de Marcelo. Nesse contexto, a decisão de Marcelo de levar as mais belas obras de arte de Siracusa para Roma merece de Plutarco uma interpretação positiva: ${ }^{14}$

"Quando os Romanos chamaram Marcelo para a guerra que se fazia no próprio país e perto
da cidade, ele tirou, no regresso, a maior parte e as mais belas obras de arte existentes em
Siracusa, com a intenção de mostrar o seu triunfo e ornamentar a cidade. De facto, Roma não
tinha nem conhecia antes nenhuma dessas elegâncias e magnificências, nem tinha amor por
este tipo de beleza e pela delicadeza da arte, mas estava repleta de armas bárbaras e despojos
ensanguentados, e coroada com monumentos e troféus dos triunfos. Não era um espectáculo
alegre nem tranquilo, nem para espectadores timidos e delicados. Porém, tal como Epaminondas

${ }^{13}$ Além disso, percebemos, em definitivo, na synkrisis (6.2-3), que o rapto das Sabinas tem outro alcance: "Contudo, Rómulo, antes de mais, apesar de ter raptado quase oitocentas mulheres, não as guardou a todas para si mas apenas a Hersília, segundo se conta, repartindo as restantes pelos cidadãos que não estavam casados. Mais tarde e na sequência destes acontecimentos, o respeito, amor e correç̧ão que observaram no trato com as mulheres transformaram aquela violência e injustiça no acto mais belo e politicamente mais proveitoso para a comunidade. E assim, misturou uns com os outros e fundiu os dois povos, preparando o Estado para a torrente futura de abundância de poder. E quanto ao pudor, amizade e firmeza que logrou incutir nos matrimónios, pode servir de testemunha o tempo". (trad. de D. Leão 2006). Desta forma, o rapto da Sabinas, mais do que um acto de guerra, é para Plutarco a base da consolidação social, assente em matrimónios estáveis, o que permite a Rómulo construir os fundamentos do futuro poder romano, algo que Teseu não conseguiu com o sinecismo. Se Rómulo procurou construir de raiz uma cidade, Teseu intentou algo mais ousado e, sem dúvida, mais arrojado, que foi a dissolução de povos e a alteração das instituições tradicionais destes para as juntar numa só.

${ }^{14}$ Marc. 21.1-3; para uma análise sobre a relação entre a cultura grega e Marcelo neste episódio vide C. Pelling 1989: 199-208. 
chamava a planície da Beócia de orquestra de Ares e Xenofonte a Éfeso a oficina de guerra, assim também me parece que se pode dizer, segundo Pindaro, que a Roma desse tempo era o "santuário do belicoso Ares".

Por um lado, a referência a Epaminondas e a Xenofonte prova que Plutarco não esquece que também a história grega está repleta de guerras internas, que terão, porventura, relegado para segundo plano a contemplação da beleza. Ficase com a ideia de que os Gregos e os Romanos desenvolvem diferentes formas de arte, e que ambos os povos se vêem enredados, quase fatalmente, em guerras sucessivas, que os afastam da contemplação serena da arte. Por outro lado, ao citar o primeiro verso da II a Pítica de Píndaro para classificar Roma ("santuário do belicoso Ares"), Plutarco acentua o carácter bélico dos Romanos, daí aprovar o acto de Marcelo, uma vez que essa seria uma forma de educar o povo romano e de o sensibilizar para o valor das obras de arte, obras essas que, segundo Cícero (In Verr. IV 54.120-121), Marcelo depositou, em número considerável, num templo que ele próprio fundou em honra da Virtude. Porventura por usar como fonte Posidónio, mais favorável à helenização de Roma, encontramos em Plutarco um tom laudatório da atitude de Marcelo ${ }^{15}$, mas o mesmo não acontece em Políbio (9.10.1-3) nem em Tito Lívio (25.31.8-11, 25.40.1-3; 26.30.9; 26.31.9; 34.4.4), que preferem realçar o facto de a transferência das obras manifestar pouca clemência para com os Siracusanos, além de - e este é o aspecto mais importante - ter dado a conhecer o luxo aos Romanos, contribuindo para corromper os seus valores tradicionais. O próprio biógrafo refere que, nesta altura, a presença da cultura helénica não seria algo normal em Roma (Marc. 21.7):

"Todavia, Marcelo vangloriava-se destes feitos, mesmo junto dos Gregos, por ter ensinado os Romanos, que eram desconhecedores, a apreciar e a admirar as belezas e as maravilhas da Grécia."

Nesse sentido, não esconde que a introdução da beleza helénica em Roma poderia suscitar reacções diferentes, especialmente por alguns pensarem que isso iria trazer maior ódio para a cidade: ${ }^{16}$

"Por isso, Marcelo conseguiu ter maior reputação junto do povo, por ter adornado a cidade com a beleza, enquanto os mais ilustres apreciavam sobretudo Fábio Máximo." ${ }^{\text {7 }}$

Precisamente na biografia de Fábio Máximo, se descreve a acção do Cunctator, após a tomada de Tarento, quando leva para Roma uma estátua

15 Vide R. Flacelière \& É. Chambry 1966: 218, n.1, J.-L. Ferrary1988: 275, 573-578. Estes estudos notam, ao contrário do texto de Plutarco, que os Romanos já tinham tido contacto com a arte grega, quando, em 272 a. C., tomaram Tarento; vide, ainda, E. Gruen 1995: 94-103, 123-9; a propósito das fontes que Plutarco usou para compor a biografia de Marcelo, remetemos para o estudo de C. Pelling1989: 203, n. 7.

${ }_{16}$ Marc. 21.4; atitude semelhante acontece em Pel. 25, após o regresso de Pelópidas da Batalha de Leuctras.

${ }^{17}$ Cf. Fab. 22.8: praotes philantrophia de Marcelo, por oposição à fllotimia de Fábio Máximo, 
colossal de Hércules, que haveria de colocar no Capitólio, ao lado de uma estátua dele próprio, feita em bronze, montando um cavalo. $\mathrm{Na}$ interpretação de Plutarco, Fábio Máximo foi mais extravagante do que Marcelo, opinião que Tito Lívio (27.16.8) não partilha ${ }^{18}$. Tanto na biografia de Marcelo como na de Fábio Máximo, Plutarco compara os dois Romanos ${ }^{19}$, lembrando que, para Posidónio (FGrHist 87 F 42), Fábio Máximo era o thureus ("escudo") e Marcelo o csufos ("espada”). Aliás, o próprio Aníbal, conhecendo o carácter de cada um deles, dizia temer Fábio como preceptor e Marcelo como adversário, pelo facto de, respectivamente, um o impedir de fazer mal e o outro por o fazer sofrer.

Como seria de esperar, Plutarco aproveita a biografia de Péricles para manifestar a sua admiração pela construção de novos edifícios em Atenas, por se ter conseguido conjugar a beleza, a perenidade dos monumentos e a brevidade da execução (Per. 13). Mais importante para o âmbito do nosso trabalho, é a comparação que o biógrafo estabelece entre as edificações de Péricles e a grandeza das construções romanas (Comp. Per.-Fab. 3.7):

"Com a grandeza dos monumentos e templos, e com a construção dos edifícios com que Péricles embelezou Atenas nem todos as obras que se construíram em Roma antes dos Césares são dignas de serem equiparadas; aquelas, pela sua grandiosidade e elegância, tinham uma tal supremacia que nada lhes era comparável."

A este respeito, M. H. Rocha Pereira (1999: 18) recorda a descrição que é feita do Templo de Júpiter Capitolino, na biografia de Publicola (15.4), onde se critica a forma como os Romanos tentaram aperfeiçoar as colunas inicialmente talhadas em Atenas, pois isso levou a que perdessem a sua beleza original.

Estes exemplos sobre considerações estéticas servem para percebermos que Plutarco contrapõe à grandeza da construção imperial a maior finura helénica e, além disso, temos de observar que ocupa pouco espaço na narrativa biográfica a descrição física de Roma. Interessa sobretudo a Plutarco analisar, por exemplo, a posição conservadora de Catão Censor contra os efeitos da introdução da cultura helénica na Vrbs (Cat. Ma. 23.3), de forma a introduzir uma opinião determinante: a paideia ajudou Roma a atingir a akme.

A par disso, há um conjunto de heróis plutarquianos cuja acção se desenvolve fora de Roma. Sertório e César pertencem a esse grupo. Embora algumas fontes historiográficas caracterizem Sertório como um homem cruel, licencioso ou mesmo um traidor, Plutarco traça um retrato mais favorável, provavelmente por

apesar de, ao longo da biografia do Cunctator, Plutarco realçar sobretudo a sua praotes philantrophia; vide Marc. 1.3, 19.4, 20.1, 23.8 (praotes philantrophia); por curiosidade, refira-se que o par Per.-Fab. é o que conta com mais ocorrências do vocábulo praotes (doze vezes).

18 A atitude de Marcelo tornou-se um topos da historiografia romana, sendo confrontada com o que Fábio Máximo fez com as estátuas tarentinas; cf. J.-L. Ferrary 1988: 510, 575 ss. .

${ }^{19}$ Cf. Marc. 9.5-6 e Fab. 19.4; vide ainda Marc. 21.4-7. 
ter usado como principal fonte Salústio ${ }^{20}$, que é mais hostil em relação a Pompeio. De forma a elogiar a megalophrosyne do romano, Plutarco lembra como respeitou o mos maiorum ao tratar de forma digna os senadores que tinham fugido de Roma, constituindo o "senado sertoriano"21, não para fundar um império concorrente do romano, mas para não permitir que os bárbaros pudessem colocar em perigo os interesses de Roma. Escreve Plutarco (Sert. 22.7-8):

\begin{abstract}
"Sertório, no fundo, era um homem que amava a pátria e que tinha um grande desejo de a ela regressar. Porém, mesmo sofrendo desventuras, procedia como um homem corajoso, e não se deixava humilhar à frente dos inimigos; nas vitórias, transmitia a Metelo e a Pompeio que estava disposto a depor as armas e a viver como um simples cidadão, logo que obtivesse autorização para regressar. De facto, desejava mais ser em Roma o mais obscuro dos cidadãos do que, sendo fugitivo, ser proclamado um general absoluto de todos os outros juntos." 22
\end{abstract}

Plutarco recorda, além disso, que o Cunctator se recusou a ajudar a retirar províncias asiáticas aos Romanos, mesmo com a promessa de dinheiro e de barcos por parte dos embaixadores de Mitridates (Sert. 23.7). Sertório é, assim, um philopatris, que deseja regressar a Roma, ainda que tivesse consciência de que o Senado não deixaria ficar sem punição as suas acções.

Quanto a César, uma parte significativa da biografia descreve os seus feitos fora de Roma. Contudo, isso não impede Plutarco de tecer algumas considerações sobre a cidade: menciona a formação de um partido contra César (26.1) e enfatiza o desgoverno (28.4-5), a corrupção (33.2) e a instabilidade que se apoderava das várias classes sociais da Vrbs (34.3) que era, segundo o biógrafo, uma cidade à deriva, tal como um barco no meio da tempestade. Lembre-se, ainda, que é longe da capital do Império que César recebe, por carta, a notícia da morte da sua filha Júlia, que morreu de parto em casa de Pompeio (23.5).

Por fim, gostaríamos de fazer uma breve referência à biografia de Coriolano. Nela, Roma é descrita como um espaço de enorme instabilidade social, a ponto de os pobres (penetes) preferirem abandonar a cidade, de forma a evitarem combater ao serviço dos ricos (plousioi) (6.1). A este respeito, Plutarco não

\footnotetext{
${ }^{20}$ As fontes historiográficas diferem na imagem que transmitem de Sertório, pois ele tanto é descrito com as características enunciadas como é generoso, moderado, virtuoso e austero; vide M. Neira (1986: 189-211); Plutarco terá usado como fonte a obra histórica de Posidónio, que não nos chegou, mas sobre a qual podemos ter alguma informação por intermédio de Diodoro Sículo, historiador que se terá baseado, para a figura de Sertório, na obra de Posidónio; Diodoro Sículo (37.22), a propósito do ethos de Sertório, refere que ele não era moderado nem tinha como qualidade a philanthropia; para C. Konrad (1994: liii-lvi), Salústio terá sido a principal fonte de Plutarco (cf. C. Jones 1971: 86 e D. Russel 22001: 54); Plutarco cita Salústio, por exemplo, em Luc. 11.5 e 33.3.vide, ainda, L. García Moreno 1992: 135 ss. e B. Scardigli 1971:33-64.

${ }^{21}$ Ao qual apenas Apiano (108.507) faz referência.

${ }^{22}$ Quando César, depois de atravessar os Alpes, passa um pequena povoação bárbara, os companheiros perguntam-lhe se ali também havia lutas e invejas entre os homens para ocuparem os cargos de poder, e ele, em sentido inverso das palavras de Sertório, respondeu: "eu preferia ser entre eles o primeiro do que o segundo entre os Romanos" (Caes. 11.4).
} 
deixa também de referir uma das características mais importantes dos primeiros tempos da República: a hostilidade entre patrícios e plebeus (24.1), tendo os primeiros acusado o povo do exílio de Coriolano, facto que esteve na origem de várias revoltas dentro da cidade, uma vez que o Senado não revogava a sentença, apesar de a maioria do povo ter uma opinião contrária (29.4).

Em conclusão, a representação de Roma nas Vidas Paralelas coaduna-se com a concepção plutarquiana de criar um equilíbrio e uma cooperação entre a missão imperial dos Romanos e a cultura helénica. Da mesma maneira que Alexandre conseguiu por meio da conquista difundir os valores do helenismo, assim também a nova ordem deverá, segundo Plutarco, ter como fundamento esses valores. Roma, uma "cidade grega", como vimos, poderá incorporar a paideia, recordando-se que já Dionísio de Halicarnasso ${ }^{23}$ vê Roma como uma escola da paideia, desvanecendo-se a imagem dos Romanos como bárbaros. $\mathrm{Na}$ verdade, Plutarco não esconde a sua admiração pelo poder de Roma, em especial pela sua grandiosidade ${ }^{24}$ e engenho militar, além de considerar Roma um local sagrado, centro do mundo habitado e civilizado ${ }^{25}$, embora entenda que falte profundidade espiritual ao imperialismo romano, e daí denunciar, como fizera Políbio (9.10), a corrupção que alastrava na Vrbs.

\section{Bibliografia}

C. Ando (1999), "Was Rome a polis?", CA 18.1 5-34.

E. Bowie (1991), "Hellenes and Hellenism in writers of the Early 2nd Sophistic”, in S. Saï (ed.), Hellenismos. Quelques jalons pour une histoire de l'identité grecque. Leiden, New York. Kobenhavn, Koln 183-204.

R. Flacelière \& É. Chambry (1966), Plutarque. Vies. Tome IV: Timoléon-Paul Émile. Pélopidas-Marcellus. Paris, Les Belles Lettres.

J.-L. Ferrary (1988), Philhellénisme et impérialisme. Aspects idéologiques de la conquête romaine du Monde hellénistique. Roma.

E. Gabba (1991), Dionysius and the history of Archaic Rome. Berkeley, Los Angeles, Oxford.

L. García Moreno (1992), "Paradoxography and Political Ideals in Plutarch's Life of Sertorius", in Ph. Stadter (Ed.), Plutarch and the Historical Tradition, London 132-158.

E. Gruen (1995), Culture and National Identity in Republican Rome. Cornell University Press.

${ }^{23}$ A propósito da presença de Roma e da Grécia na obra de Dionísio de Halicarnasso, vide F. Hartog (1991: 149-167).

${ }^{24}$ Cf. De fort. Rom. 316C, 316E-F, 325D-E.

${ }^{25}$ Cf. Ibid. 317 A. 
F. Hartog (1991), «Rome et la Grèce: les choix de Denys d'Halicarnasse», in

S. Saï (Ed.), Hellenismos. Quelques jalons pour une histoire de l'identité grecque. Leiden, New York, Kobenhavn, Koln 149-167.

C. Jones (1971), Plutarch and Rome. Oxford.

C. Konrad (1994), Plutarch's Sertorius: a bistorical commentary. Chapel HillLondon, The University of North Carolina Press.

D. Leão (2006), Plutarco. Vida de Rómulo. Coimbra.

M. Lopez Salvà (1990-1), "Reflexiones de Plutarco e Díon de Prusa sobre las ciudades griegas del este y su relación com Roma", Faventia 12-13 25-36.

M. Neira (1986), "Aportaciones al estudio de las fuentes literarias antiguas de Sertorio", Gerión 4 189-211.

A. Nikolaidis (1986), "Ellenikos-Barbarikos. Plutarch on Greek and Barbarian Characteristics", WS 20 229-244.

C. Pelling (1989), "Plutarch: Roman heroes and Greek culture", in M. Griffin \& J. Barnes (Eds.), Philosophia Togata. Essays on Philosophy and Roman Society. Oxford 199-232.

R. Preston (2001), "Roman Questions, Greek Answers: Plutarch and the construction of identity", in S. Goldhill (ed.), Being Greek under Rome. Cultural Identity, the second Sophistic and the Development of Empire. Cambridge 86-119.

M.H. da Rocha Pereira (1999), "Introdução", in Plutarco. Vida de Sólon. Lisboa 7-26.

D. Russel (2001), Plutarch, foreword and bibliography by Judith Mossman. London.

S. Saï et al. (Eds., 2004), Histoire de la Littèrature Grecque.Paris, PUF.

B. Scardigli (1971), "Considerazioni Sulle Fonti Della Biografia Plutarchea di Sertorio", SFII 43 33-64.

Swain, S. (1989a), "Plutarch's De fortuna romanorum", CQ 39 504-516.

(1989b), "Plutarch: Chance, Providence, and History", AJP 110 272-302. 